\title{
Potential Role of Chloroquine in Macrophageal Iron Mobilization
}

\section{Nweneka CV}

National Agency for the Control of AIDS (NACA), Central Area, Abuja, Nigeria

*Corresponding author: Nweneka CV, National Agency for the Control of AIDS (NACA), Plot 823, Ralph Shodeinde Street, Central Area, Abuja, Nigeria, Tel: +234 706 958 1036; E-mail: chidinweneka@hotmail.com

Received date: August 29, 2016; Accepted date: September 16, 2016; Published date: September 19, 2016

Copyright: () 2016 Nweneka CV. This is an open-access article distributed under the terms of the Creative Commons Attribution License, which permits unrestricted use, distribution, and reproduction in any medium, provided the original author and source are credited.

\begin{abstract}
Malaria anaemia is still a major killer of children in malaria endemic countries. We have shown from the published literature that malaria anaemia, especially mild to moderate anaemia is largely due to inflammation-induced hypoferreamia and immune-mediated destruction of parasitized and non-parasitized red blood cells. In this review, we speculate that the immunomodulatory and anti-inflammatory properties of chloroquine, a cheap, readily available antimalarial, may make it a very good candidate for investigation as a possible adjunct treatment for malariaassociated anaemia
\end{abstract}

Keywords: Malaria; Anaemia; Chloroquine; Immune-modulation; Anti-inflammatory

\section{Introduction}

Anaemia remains a major global public health problem, affecting about 2 billion people, $89 \%$ of who live in developing countries [1,2]. It reduces the quality of life of children, and is a significant cause of morbidity and mortality in children and pregnant women $[2,3]$. While globally, the commonest cause of anaemia is iron deficiency [3-5], in malaria endemic areas, malaria contributes significantly to the pathogenesis of anaemia [3,5]. In such settings, poor response to treatment due to either inappropriate treatment or resistance to the antimalarial drugs by Plasmodium increase the risk of anaemia [6]. The complex pathogenesis of malaria-associated anaemia and the controversies generated by the perceived effect of iron administration on morbidity during malaria calls for alternative interventions to combat malaria-associated anaemia.

Chloroquine, a drug that has traditionally been used as a first line antimalarial has been noted to possess a number of actions separate from its antimalarial properties, which has seen it used in many settings. Its good safety profile, wide availability, and relatively low cost make it an attractive candidate for investigation on possible roles in combating malaria-associated anaemia. This review examines the pharmacology of chloroquine and relates this to the pathophysiology of malaria-associated anaemia to assess the possible use of chloroquine in the management of malaria anaemia.

\section{Malaria-associated anaemia}

Malaria-associated anaemia has been defined as a reduction in the haemoglobin or haematocrit below normal for age, sex and state of pregnancy, in the presence of malarial parasitaemia of any density in endemic areas [7].

The pathophysiology of malaria anaemia involves iron delocalisation mediated by cytokines and hepcidin, similar to the pathophysiology of anaemia of inflammation [8]. Erythrocytes are lost during malaria through hemolysis of parasitized red blood cells, erythrophagocytosis of parasitized and unparasitized RBC, hypersplenism, autoimmune hemolysis from the deposition of immunoglobulins on the surfaces of red blood cells, and hapteninduced intravascular haemolysis resulting in haemoglobineamia and haemoglobinuria [6,7,9-10].

Reduced erythropoiesis in malaria results from hypoactivity of the bone marrow with poor response to erythropoietin (EPO), probably mediated by a serum factor that suppresses the growth of the burstforming unit-erythron (BFU-E) and the colony forming unit-erythron (CFU-E), and inadequate production of erythropoietin by inflammatory mediators such as tumour necrosis factor- $\alpha$ (TNF- $\alpha$ ) $[11,12]$. Other mechanisms for reduced RBC production include malaria-induced dyserythropoiesis, especially in persons with recurrent malaria $[13,14]$, and disturbances in serum cytokine levels involving raised serum TNF- $\alpha$, IL-10 and IFN- $\gamma[11,13,15,16]$.

Co-morbidities especially with bacteria and viruses which are consequences of the immunosuppressive effects of $P$. falciparum malaria also contribute to reduced RBC production leading to anaemia. Parvovirus B19 has been particularly suggested as an important contributor to malaria anaemia because of its high prevalence among children in developing countries, and the tropism of the virus for erythroid progenitor cells. Recent studies have found a significant association between co-infection with pavovirus B19 with severe anaemia in Ghanaian and Gabonese children with malaria $[17,18]$

Folate deficiency is thought to play a minor role in the development of malaria anaemia [19-21]. In contrast, iron deficiency might develop during malaria through reduced intake from anorexia, reduced absorption, and increased loss in haemoglobinuria. Furthermore, poor dietary intake of iron could result in background iron deficiency which becomes more obvious during malaria.

The controversy regarding the benefit of giving iron to children with malaria, following reports of increased morbidity and mortality among children living in malaria endemic areas who were given iron supplements, necessitates the search for a more acceptable therapeutic option for combating malaria anaemia. Besides, there have been conflicting reports on the benefits of iron supplementation during acute malaria attack. Results of a case control study from the Gambia 
suggest that increase $\mathrm{Hb}$ following an episode of malaria infection was unlikely to be due to iron supplementation [22]. The study compared the absorption of isotope-labelled iron in children with either presumed iron-deficiency alone or anaemia post-malaria. While haemoglobin increase was significantly higher at both days 15 and 30 post malaria in the malaria group compared to the group with presumed iron deficiency alone, incorporation of isotope labelled iron was significantly reduced in the malaria group. This finding collaborates those from a randomised control trial in Tanzania [23] in which 100 children with $\mathrm{Hb}<5 \mathrm{~g} / \mathrm{dL}$ and a positive smear for malaria parasite, were randomised to receive either iron supplementation in addition to malarial treatment (quininine plus fansidar), or only malarial treatment. The $\mathrm{Hb}$ rise at 2 weeks and 12 weeks, respectively, was $3.7 \mathrm{~g} / \mathrm{dL}$ and $9.2 \mathrm{~g} / \mathrm{dL}$ in the group that received iron supplementation plus malarial treatment, and $3.5 \mathrm{~g} / \mathrm{dL}$ and $9.0 \mathrm{~g} / \mathrm{dL}$ in the group that received only malarial treatment, suggesting that iron supplementation did not affect the recovery of haemoglobin level in children with malaria-associated anaemia in this study. However, other studies have reported beneficial effects among iron supplemented children with malaria [24-26].

\section{Iron metabolism in malaria}

Body's iron is regulated primarily by iron absorption from the small intestine. There are no known specialised excretory pathways for iron in the body, and variable amounts are lost from desquamation of skin and mucosal cells. The factors that determine that amount of iron absorbed include a physiological need for iron, dietary iron intake, bioavailability of dietary iron and the ability of the mucosal cell to adapt to body's dietary needs [27]. Under normal physiological conditions, about 1-2 mg of iron is absorbed from the intestine daily, but this can be upregulated in iron deficiency states. However, the bulk of the body's iron requirements are met by the recycling of iron by the reticulo-endothelial system (monocyte-macrophage system), which is responsible for the phagocytosis and catabolism of senescent erythrocytes.

A ferrireductase at the intestinal brush border reduces ingested iron from the ferric to ferrous form, which is then actively transported across the apical enterocyte membrane by divalent metal transporter 1 (DMT1), also called natural resistance-associated macrophage protein 2 (NRAMP-2). The iron in the enterocyte can either be transported out of the cell by the action of ferroportin 1 (an active iron exporter) and hephaestin (a ferrooxidase), or lost when the enterocyte sloughs off. Iron in the body is stored as ferritin (labile, readily accessible), haemoglobin, and hemosiderin (insoluble iron found mostly in macrophages). Macrophages acquire iron from various iron-containing proteins in the body such as transferrin, lactoferrin, haptoglobin-Hb complexes, senescent red blood cells and possibly direct uptake of ferric and ferrous iron $[28,29]$. The iron acquired by macrophages and hepatocytes are re-exported for use by the bone marrow for erythropoiesis.

Inflammation induces hypoferraemia through sequestration of iron by the reticuloendothelial system and decreased intestinal iron absorption [30,31], mediated by hepcidin, a disulfide-bonded 25 amino acid peptide produced in the liver $[32,33]$. Similarly, malariainduced inflammation impedes iron flux within the macrophagemonocyte system making iron unavailable to the marrow cells for erythropoiesis [34]. The effect of Plasmodium infection on erythropoietin production is unclear. While animal studies suggest a vigorous host erythropoietin response to Plasmodium infection [13], humans have shown conflicting results (reviewed by Menendez et al. [7]). And as already discussed, disordered cytokine response, many of which remain elevated for weeks after successful treatment for malaria, contributes to the pathogenesis and persistence of malaria anaemia [35]. The resolution of malaria anaemia therefore could be the result of iron re-mobilization in the macrophage-monocyte system following resolution of the malaria-induced inflammatory process; in which case administration of exogenous iron in malaria anaemia might be of little benefit to the recipients, thus accounting for the conflicting reports from iron supplementation studies.

In the search for alternative therapeutic approaches to malaria anaemia, one of the first areas of interest would be the antimalarials because the discovery of an effective antimalarial with an additional property of enhancing haematologic recovery will be of immense economic and clinical advantage.

\section{Potential role of chloroquine in macrophageal iron mobilization}

Almost globally abandoned as an antimalarial because of high rates of resistance, chloroquine could be an important adjunct treatment for malaria anaemia. It is widely acknowledged that even in areas where chloroquine resistance is high; the use of chloroquine could still confer some clinical and parasitological benefit. One of the properties that gives chloroquine this advantage is its antipyretic actions which provide relief to the patients. In addition to being cheap, safe and widely available, chloroquine is likely to return to use in much of the regions where it has previously been abandoned. For example, there have been reports of the return of chloroquine efficacy in Malawi 12 years after its withdrawal from use [36]. It is likely that similar experiences will be reported in other areas where chloroquine had been abandoned due to high resistance. Another reason chloroquine is attractive for investigation of a possible effect in macrophageal iron mobilization is because chloroquine has several pharmacological properties in addition to its antimalarial actions. As already mentioned, chloroquine has antipyretic properties; it also has antiinflammatory activities for which it is used in many inflammatory conditions such as rheumatoid arthritis and connective tissue diseases.

\section{Chloroquine pharmacodynamics}

Chloroquine is a 7-chloro-4-[[4-(diethylamino)-1methylbutyl]amino] quinoline- (molecular formula: C18H26ClN3), and has the following structural formula (Scheme 1).

It is a weak base and raises the endocytic and lysosomal $\mathrm{pH}$ of eukaryotic cells [37]. Chloroquine is rapidly and almost completely absorbed from the gastrointestinal tract, with only a small proportion appearing in the stool [38]. Peak plasma levels of $60-90 \mathrm{ng} / \mathrm{mL}$ are attained within 1-6 h following a single oral dose of $300 \mathrm{mg}$ base of chloroquine, although there is considerable inter-individual variation, and depending on whether or not it is taken with food [38-40]. The absorption is also very good when given intramuscularly and via nasogastric tube. Chloroquine has a strong affinity for blood constituents particularly thrombocytes and granulocytes which reduces the plasma concentrations [41,42]. In addition, about $46-74 \%$ of chloroquine in the plasma is bound to plasma proteins mainly albumin and a-acid glycoprotein [43,44]. It is also avidly bound to several tissues in the body. In animals, from 200 to 700 times the plasma concentration may be found in the liver, spleen, kidney, and lung [45], and some melanin-containing tissues such as the retina, the 
Page 3 of 6

inner ear and hair follicles [46]. The brain and spinal cord, in contrast, contain only 10 to 30 times the amount present in plasma [45].

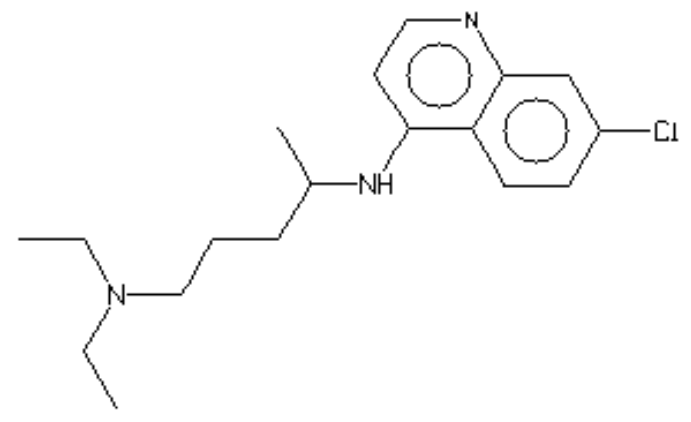

Scheme 1: Chloroquine.

Excretion of chloroquine is quite slow, but is increased by acidification of the urine. Chloroquine undergoes appreciable degradation in the body. The main metabolite is desethylchloroquine, which accounts for one fourth of the total material appearing in the urine; bisdesethylchloroquine, a carboxylic acid derivative, and other metabolic products as yet uncharacterized are found in smaller amounts. Slightly more than half of the urinary drug products can be accounted for as unchanged chloroquine. Chloroquine is eliminated slowly from the body and can be detected in the urine for more than a year after intake [47]. It has a multiexponential elimination pattern with an initial elimination phase with a half life of 3-6 days followed by a slower phase with a half life of 12-14 days. Terminal elimination of half-lives of chloroquine and its metabolite diethylchloroquine of up to 2 months have been reported, although it is thought that this half life is of minor importance in the elimination of the drug from the body. Between $45 \%$ and $56 \%$ of the total dose of chloroquine is eliminated from the urine within $3-13$ weeks and about $8-10 \%$ are eliminated in the feaces [47].

\section{Mechanisms of action of chloroquine}

Chloroquine is primarily used as an antimalarial drug. It is a potent schizontocidal drug which is highly effective against the asexual forms of all the four species of Plasmodium that cause malaria in man $-P$. falciparum, ovale, vivax and malariae. In addition, it is active against the gametocytes of $P$. vivax, ovale and malariae but not against the gametocytes of $P$. falciparum [47]. It is thought that the mechanism of action of chloroquine against Plasmodium relates to its inhibition of the enzyme that polymerises and detoxifies ferriprotoporphyrin IX in the parasite food vacuole $[48,49]$. Chloroquine accumulates in the acid food vacuole of the intra-erythrocytic stage malaria parasite. The food vacuole primarily serves to degrade ingested red cell haemoglobin to provide the growing parasite with needed amino acids. This process releases haem which in the soluble form is harmful to biological membranes and inhibits a variety of enzymes. To avert this potential danger, the parasite detoxifies the haem by incorporating it into an insoluble crystalline compound called haemozoin or malaria pigment. A component of the Plasmodium trophozoites promotes the polymerization of haem to form haemozoin. This heme polymerase activity is inhibited by chloroquine [49] by forming molecular complexes with plasmodial DNA, thereby inhibiting plasmodial DNA synthesis $[50,51]$.

\section{Other pharmacologic effects of chloroquine}

In addition to the above antimalarial actions, there is abundant evidence that chloroquine has several other actions on a number of cell types. For example, AtT-20 cells (a mouse pituitary gland tumour cell line) secrete ACTH by cleaving the precursor to ACTH and bendorphin. These hormones are stored in secretory granules and discharged only in the presence of a secretagogue. Chloroquine blocks the storage of newly synthesized ACTH in the secretory granules and instead diverts it to the outside of the cell [52]. Chloroquine also inhibits a number of thiol-containing enzymes including alcohol dehydrogenase, a mechanism thought to be responsible for chloroquine-induced retinopathy [53], and blocks the actions of endogenous as well as exogenous histamine in guinea-pigs [54], blocks histamine induced broncho-constriction in animal models [55] and decrease antigen-induced bronchoconstriction in guinea pig trachea [56]. It has also been shown to have a steroid-sparing effect [57]. In patients with asthma, administration of hydroxychloroquine (a derivative of chloroquine) at a dose of $300-400 \mathrm{mg} /$ day $(\max 6.5$ $\mathrm{mg} / \mathrm{kg}$ ) in adult asthmatics, including steroid dependent asthmatics, led to improvement of symptoms [58]. Chloroquine has also been noted to inhibit the replication of a number of viruses such as HSV-1 virus [59], HIV-1 and several AIDS related opportunistic microorganisms $[60,61]$. It is thought that the inhibitory action of chloroquine on HIV acts at several targets in the HIV life cycle, including inhibition of the HIV-1 integrase and Tat-mediated transactivation, and reduction of iron stores within cells affecting reverse transcription [62-64]. Other anti-HIV effects of chloroquine include inhibition of post-transcriptional maturation of gp120 [65]. It has been suggested that chloroquine is effective in inhibiting the effects of the lethal factor of anthrax $[66,67]$.

Chloroquine has an anti-mutagenic effect [68]. It binds strongly to nucleic acids particularly to CG sequence of DNA, reinforcing its structural configuration and preventing mutagenesis, and improves the cell mechanism of DNA repair from the damage induced by alkylating therapy $[69,70]$. By inhibiting phospholipase A2 and tumour necrosis factor, chloroquine acts as an immunomodulator [71,72]; and also act as a lysosome-stabilizing agent.

\section{Chloroquine and iron metabolism}

The role of chloroquine in iron metabolism is still poorly understood. However, there is abundant evidence to suggest that many of the effects of chloroquine on organisms results from the interference with intracellular free iron which deprives the organisms from the iron needed for metabolism. Chloroquine, being a weak base, accumulates in acid intracellular compartments increasing the intracellular $\mathrm{pH}$. Legssyer and co-workers have shown that chloroquine significantly reduces incorporation of iron into the liver, spleen and alveolar macrophages of animals loaded in vivo with iron dextran [73]. They assessed the haematological parameters and iron load in male Wister rats that had either been loaded with iron using iron dextran, or made iron deficient by being fed with iron depleted diet over a 5 week period. Chloroquine was administered to these rats beginning one week prior to iron-loading or depleting schedule till the end of the experiment. They found that the uptake of iron by the bronchoalveolar macrophages after iron dextran loading in rats treated with chloroquine was about $400 \%$ lower than in rats not treated with chloroquine. Furthermore, chloroquine interferes with the transferrintransferrin receptor pathway and phagocytosis, and inhibits the uptake of radioactive iron in a dose dependent manner in both neuronal and 
glial cells in vitro, and significantly reduced nitrite release in primary cultures of macrophages from iron loaded rats treated with chloroquine [73].

Mobilization of iron from transferrin and ferritin depends on an acidic environment. At higher $\mathrm{pH}$, iron remains bound to transferrin, and therefore unavailable. Chloroquine therefore interferes with intracellular free iron availability without affecting the level of iron complexed into organic molecules [74]. Intracellular ferritin iron is used for heme synthesis through a process requiring proteolytic ferritin degradation in a lysosomal-like compartment [75]. Chloroquine by raising the $\mathrm{pH}$ of the monocytes, limits iron availability. The growth inhibitory effects of chloroquine on legionella pneumophilia [37], Histoplasma capsulatum [76] and Franscisella tularensis [77] depend on its ability to limit iron availability in the phagolysosome. Other organisms that are inhibited by chloroquine through iron deprivation are HIV-1 and HSV [64,65].

\section{Chloroquine and post malaria anaemia}

Is there a role for chloroquine in improving the erythropoietic response post malaria? It is difficult to say with certainty what the role chloroquine would play in enhancing haemopoietic response during malaria. But it is obvious that whatever role it would play will depend on the relative importance of each of the multifarious effects of chloroquine and the pre-morbid status of the patient, and other features of the index illness. In a patient who was already iron-deficient prior to malaria, chloroquine administration could worsen the anaemia because of its tendency to create an intracellular iron deficient state. On the other hand, in pre-morbidly iron sufficient patients, the importance of chloroquine-induced iron deprivation will be lower than its immune modulatory effects. Thus the anti-inflammatory properties of chloroquine and its effect on oxidative stress could advantageously reduce malaria-induced hemolysis and modulate most of the inflammatory effects of malaria, thus allowing for a faster haematologic recovery (Figure 1).

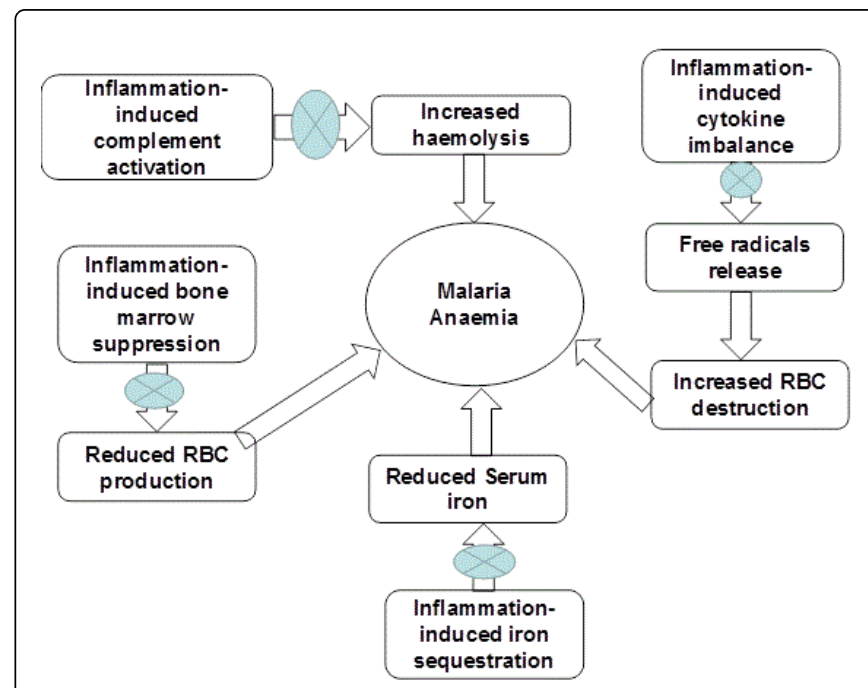

Figure 1: Potential points of action of chloroquine to enhance erythropoietic recovery post-malaria anaemia.

Increased serum levels of TNF- $\alpha$, IFN- $\gamma$ and nitric oxides depress erythropoiesis via bone marrow depression, dyserythropoiesis and erythrophagocytosis, and also by direct inhibition of erythropoiesis. Chloroquine on the other hand interferes with the pathways responsible for the production of these products. It is likely therefore that by inhibiting the production of these toxic chemicals, chloroquine minimises the erythropoietic insults and aids erythropoietic recovery post-malaria.

Co-morbidities during malaria contribute to malaria-associated anaemia. The inhibitory effects of chloroquine on many microorganisms could contribute to the resolution of malaria anaemia by reducing the incidences of concurrent infections. The different actions of chloroquine might appear paradoxical; however, this could be Nature's back-up mechanism in which chloroquine while restricting access to life-giving iron for the pathogens, helps to alleviate some of the negative consequences of the prevailing infection. Since many of the actions of chloroquine are still poorly understood, this drug merits further investigation on any possible role in enhancing haematopoietic recovery post-malaria.

\section{References}

1. Kassebaum NJ (2016) The Global Burden of Anemia. Hematol Oncol Clin 30: 247-308.

2. Pasricha SR, Drakesmith H (2016) Iron Deficiency Anemia: Problems in Diagnosis and Prevention at the Population Level. Hematol Oncol Clin 30: 309-325.

3. Kassebaum NJ, Jasrasaria R, Naghavi M, Wulf SK, Johns N, et al. (2014) A systematic analysis of global anemia burden from 1990 to 2010. Blood 123: 615-624.

4. Frewin R, Henson A, Provan D (1997) ABC of clinical haematology: Iron deficiency anaemia. BMJ 314: 360-363.

5. Stevens GA, Finucane MM, De-Regil LM, Paciorek CJ, Flaxman SR, et al. (2013) Global, regional, and national trends in haemoglobin concentration and prevalence of total and severe anaemia in children and pregnant and non-pregnant women for 1995-2011: a systematic analysis of population-representative data. The Lancet Glob Health 1: e16-25.

6. TDR (2001) The Prevention and Management of Severe Anaemia in Children in Malaria-endemic regions of Africa: A review of Research. Geneva pp:1-42.

7. Menendez C, Fleming AF, Alonso PL (2000) Malaria-related anaemia. Parasitol Today 16: 469-476.

8. Nweneka CV, Doherty CP, Cox S, Prentice A (2010) Iron delocalisation in the pathogenesis of malarial anaemia. Trans R Soc Trop Med Hyg 104: 175-184.

9. Schwartz RS, Olson JA, Raventos-Suarez C, Yee M, Heath RH, et al. (1987) Altered plasma membrane phospholipid organization in Plasmodium falciparum-infected human erythrocytes. Blood 69: 401-407.

10. Bouanga JC, Danis M, Mazier D, Gentilini M (1994) Alterations of uninfected red blood cells in malaria. Parasitol Res 80: 70-73.

11. Miller KL, Silverman PH, Kullgren B, Mahlmann LJ (1989) Tumor necrosis factor alpha and the anemia associated with murine malaria. Infect Immun 57: 1542-1546.

12. Clark IA, Chaudhri G (1988) Tumour necrosis factor may contribute to the anaemia of malaria by causing dyserythropoiesis and erythrophagocytosis. Br J Haematol 70: 99-103.

13. Greenberg PL, Gordeuk V, Issaragrisil S, Siritanaratkul N, Fucharoen S, et al. (2001) Major hematologic diseases in the developing world- new aspects of diagnosis and management of thalassemia, malarial anemia, and acute leukemia. Hematology Am Soc Hematol Educ Program 479-498.

14. Phillips RE, Pasvol G (1992) Anaemia of Plasmodium falciparum malaria. Bailliere's Clin Haematol 5: 315-330. 
15. Biemba G, Gordeuk VR, Thuma P, Weiss G (2000) Markers of inflammation in children with severe malarial anaemia. Trop Med Int Health 5: 256-262.

16. Thawani N, Tam M, Chang KH, Stevenson MM (2006) Interferongamma mediates suppression of erythropoiesis but not reduced red cell survival following CpG-ODN administration in vivo. Exp Hematol 34: 1451-1461.

17. Duedu KO, Sagoe KWC, Ayeh-Kumi PF, Affrim RB, Adiku T (2013) The effects of co-infection with human parvovirus B19 and Plasmodium falciparum on type and degree of anaemia in Ghanaian children. Asian Pac J Trop Biomed 3: 129-139.

18. Toan NL, Sy BT, Song LH, Luong HV, Binh NT, et al. (2013) Co-infection of human parvovirus B19 with Plasmodium falciparum contributes to malaria disease severity in Gabonese patients. BMC Infect Dis 13: 375.

19. van Hensbroek MB, Morris-Jones S, Meisner S, Jaffar S, Bayo L, et al. (1995) Iron, but not folic acid, combined with effective antimalarial therapy promotes haematological recovery in African children after acute falciparum malaria. Trans R Soc Trop Med Hyg 89: 672-676.

20. Abdalla SH (1990) Iron and folate status in Gambian children with malaria. Ann Trop Paediatr 10: 265-272.

21. BradLey-Moore AM, Greenwood BM, BradLey AK, Akintunde A, Attai ED, et al. (1985) Malaria chemoprophylaxis with chloroquine in young Nigerian children. IV. Its effect on haematological measurements. Ann Trop Med Parasitol 79: 585-595.

22. Doherty CP, Cox SE, Fulford AJ, Austin S, Hilmers DC, et al. (2008) Iron Incorporation and Post-Malaria Anaemia. PLoS ONE 3: e2133.

23. van den Hombergh J, Dalderop E, Smit Y (1996) Does iron therapy benefit children with severe malaria-associated anaemia? A clinical trial with 12 weeks supplementation of oral iron in young children from the Turiani Division, Tanzania. J Trop Pediatr 42: 220-227.

24. Menendez C, Kahigwa E, Hirt R, Vounatsou P, Aponte JJ, et al. (1997) Randomised placebo-controlled trial of iron supplementation and malaria chemoprophylaxis for prevention of severe anaemia and malaria in Tanzanian infants. Lancet 350: 844-850.

25. Desai MR, Mei JV, Kariuki SK, Wannemuehler KA, Phillips-Howard PA, et al. (2003) Randomized, controlled trial of daily iron supplementation and intermittent sulfadoxine-pyrimethamine for the treatment of mild childhood anemia in western Kenya. J Infect Dis 187: 658-666.

26. Verhoef H, West CE, Nzyuko SM, de Vogel S, van der Valk R, et al. (2002) Intermittent administration of iron and sulfadoxine-pyrimethamine to control anaemia in Kenyan children: a randomised controlled trial. Lancet 360: 908-914.

27. Roughead ZK, Hunt JR (2000) Adaptation in iron absorption: iron supplementation reduces nonheme-iron but not heme-iron absorption from food. Am J Clin Nutr 72: 982-989.

28. Olakanmi O, Stokes JB, Britigan BE (1994) Acquisition of iron bound to low molecular weight chelates by human monocyte-derived macrophages. J Immunol 153: 2691-2703.

29. Kaplan J, Jordan I, Sturrock A (1991) Regulation of the transferrinindependent iron transport system in cultured cells. J Biol Chem 266: 2997-3004.

30. Andrews NC (2004) Anemia of inflammation: the cytokine-hepcidin link. J Clin Invest 113: 1251-1253.

31. Beaumier DL, Caldwell MA, Holbein BE (1984) Inflammation triggers hypoferremia and de novo synthesis of serum transferrin and ceruloplasmin in mice. Infect Immun 46: 489-494.

32. Deicher R, Hörl WH (2004) Hepcidin: a molecular link between inflammation and anaemia. Nephrol Dial Transplant 19: 521-524.

33. Nemeth E, Rivera S, Gabayan V, Keller C, Taudorf S, et el. (2004) IL-6 mediates hypoferremia of inflammation by inducing the synthesis of the iron regulatory hormone hepcidin. J Clin Invest 113: 1271-1276.

34. Knutson M, Wessling-Resnick M (2003) Iron metabolism in the reticuloendothelial system. Crit Rev Biochem Mol Biol 38: 61-88.
35. Laufer MK, Thesing PC, Eddington ND, Masonga R, Dzinjalamala FK, et al. (2006) Return of chloroquine antimalarial efficacy in Malawi. N Engl J Med 355: 1959-1966.

36. Byrd TF, Horwitz MA (1991) Chloroquine inhibits the intracellular multiplication of Legionella pneumophila by limiting the availability of iron: a potential new mechanism for the therapeutic effect of chloroquine against intracellular pathogens. J Clin Invest 88: 351-357.

37. Krishna S, White NJ (1996) Pharmacokinetics of quinine, chloroquine and amodiaquine. Clinical implications. Clin Pharmacokinet 30: 263-299.

38. Tulpule A, Krishnaswamy K (1982) Effect of food on bioavailability of chloroquine. Eur J Clin Pharmacol 23: 271-273.

39. Ducharme J, Farinotti R (1996) Clinical pharmacokinetics and metabolism of chloroquine. Clin Pharmacokinet 31: 257-274.

40. Ferrari V, Cutler DJ (1990) Uptake of chloroquine by human erythrocytes. Biochem Pharmacol 39: 753-762.

41. Gustafsson LL, Walker O, Alván G, Beermann B, Estevez F, et al. (1983) Disposition of chloroquine in man after single intravenous and oral doses. Br J Clin Pharmacol 15: 471-479.

42. Walker O, Birkett DJ, Alván G, Gustafsson LL, Sjöqvist F (1983) Characterization of chloroquine plasma protein binding in man. Br J Clin Pharmacol 15: 375-377.

43. Giao PT, de Vries PJ (2001) Pharmacokinetic interactions of antimalarial agents. Clin Pharmacokinet 40: 343-373.

44. (2004) Chloroquine Clinical Pharmacology, RxList Inc.

45. Roque MR (2005) Chloroquine and Hydroxychloroquine Toxicity. Medscape.

46. Aden AY (1995) Chloroquine (2nd edn.) In: Handbook of Drugs for Tropical Parasitic Infections, London: Taylor \& Francis 39-46.

47. Wellems TE (1992) Malaria How chloroquine works. Nature 355: 108-109.

48. Slater AFG, Cerami A (1992) Inhibition by chloroquine of a novel haem polymerase enzyme activity in malaria trophozoites. Nature 355: 167-169.

49. Parker FS, Irvin JL (1952) The interaction of chloroquine with nucleic acids and nucleoproteins. J Biol Chem 199: 897-909.

50. Cohen SN, Yielding KL (1965) Inhibition of DNA and RNA polymerase reactions by chloroquine. Proc Natl Acad Sci USA 54: 521-527.

51. Moore HP, Gumbiner B, Kelly RB (1983) Chloroquine diverts ACTH from a regulated to a constitutive secretory pathway in AtT-20 cells. Nature 302: 434-436.

52. Fiddick R, Heath H (1967) Inhibition of alcohol dehydrogenase by chloroquine. Nature 213: 628-629.

53. Agarwal SL, Deshmankar BS (1963) The in vitro antihistaminic and antianaphylactic actions of chloroquine. Arch Int Pharmacodyn Ther 143: 401-407.

54. Ayitey-Smith E, Boye GL (1974) Effect of chloroquine on histamineinduced bronchial asthma in the guinea-pig. J Pharm Pharmacol 26: 208-209.

55. Andersson P (1982) Effects of inhibitors of anaphylactic mediators in two models of bronchial anaphylaxis in anaesthetized guinea-pigs. $\mathrm{Br} \mathrm{J}$ Pharmacol 77: 301-307.

56. Moss RB (1995) Alternative pharmacotherapies for steroid-dependent asthma. Chest 107: 817-825.

57. Charous BL, Halpern EF, Steven GC (1998) Hydroxychloroquine improves airflow and lowers circulating $\operatorname{IgE}$ levels in subjects with moderate symptomatic asthma. J Allergy Clin Immunol 102: 198-203.

58. Lancz GJ, McLaren LC, James CG, Scaletti JV (1971) Chloroquine mediated alterations in mammalian cell metabolism and viral replication. Proc Soc Exp Biol Med 136: 1289-1293.

59. Tsai WP, Nara PL, Kung HF, Oroszlan S (1990) Inhibition of human immunodeficiency virus infectivity by chloroquine. AIDS Res Hum Retroviruses 6: 481-489.

60. Boelaert JR, Appelberg R, Gomes MS, Blasi E, Mazzolla R, et al. (2001) Experimental results on chloroquine and AIDS-related opportunistic infections. J Acquir Immune Defic Syndr 26: 300-301. 
Citation: Nweneka CV (2016) Potential Role of Chloroquine in Macrophageal Iron Mobilization. Pharm Anal Acta 7: 505. doi: 10.4172/2153-2435.1000505

Page 6 of 6

61. Fesen MR, Kohn KW, Leteurtre F, Pommier Y (1993) Inhibitors of human immunodeficiency virus integrase. Proc Natl Acad Sci USA 90: 2399-2403.

62. Jiang MC, Lin JK, Chen SSL (1996) Inhibition of HIV-1 Tat-mediated transactivation by quinacrine and chloroquine. Biochem Biophys Res Commun 226: 1-7.

63. Savarino A, Gennero L, Sperber K, Boelaert JR (2001) The anti-HIV-1 activity of chloroquine. J Clin Virol 20: 131-135.

64. Savarino A, Gennero L, Chen HC, Serrano D, Malavasi F, et al. (2001) Anti-HIV effects of chloroquine: mechanisms of inhibition and spectrum of activity. AIDS 15: 2221-2229.

65. Orlik F, Schiffler B, Benz R (2005) Anthrax toxin protective antigen: inhibition of channel function by chloroquine and related compounds and study of binding kinetics using the current noise analysis. Biophys J 88: 1715-1724.

66. Komiyama T, Swanson JA, Fuller RS (2005) Protection from anthrax toxin-mediated killing of macrophages by the combined effects of furin inhibitors and chloroquine. Antimicrob Agents Chemother 49: 3875-3882.

67. Briceño E, Reyes S, Sotelo J (2003) Therapy of glioblastoma multiforme improved by the antimutagenic chloroquine. Neurosurg Focus 14: 1-6.

68. Esteller M, Garcia-Foncillas J, Andion E, Goodman SN, Hidalgo OF, et al (2000) Inactivation of the DNA-repair gene MGMT and the clinical response of gliomas to alkylating agents. N Engl J Med 343: 1350-1354.

69. O'Brien RL, Olenick JG, Hahn FE (1966) Reactions of quinine, chloroquine, and quinacrine with DNA and their effects on the DNA and RNA polymerase reactions. Proc Natl Acad Sci USA 55: 1511-1517.
70. Neale ML, Fiera RA, Matthews N (1988) Involvement of phospholipase A2 activation in tumour cell killing by tumour necrosis factor. Immunology 64: 81-85.

71. Spriggs DR, Sherman ML, Imamura K, Mohri M, Rodriguez C, et al. (1990) Phospholipase A2 activation and autoinduction of tumor necrosis factor gene expression by tumor necrosis factor. Cancer Res 50: 7101-7107.

72. Legssyer R, Ward RJ, Crichton RR, Boelaert JR (1999) Effect of chronic chloroquine administration on iron loading in the liver and reticuloendothelial system and on oxidative responses by the alveolar macrophages. Biochem Pharmacol 57: 907-911.

73. Ghigo D, Aldieri E, Todde R, Costamagna C, Garbarino G, et al. (1998) Chloroquine stimulates nitric oxide synthesis in murine, porcine, and human endothelial cells. J Clin Invest 102: 595-605.

74. Starke PE, Gilbertson JD, Farber JL (1985) Lysosomal origin of the ferric iron required for cell killing by hydrogen peroxide. Biochem Biophys Res Commun 133: 371-379.

75. Newman SL, Gootee L, Brunner G, Deepe GS Jr (1994) Chloroquine induces human macrophage killing of Histoplasma capsulatum by limiting the availability of intracellular iron and is therapeutic in a murine model of histoplasmosis. J Clin Invest 93: 1422-1429.

76. Fortier AH, Leiby DA, Narayanan RB, Asafoadjei E, Crawford RM, et al. (1995) Growth of Francisella tularensis LVS in macrophages: the acidic intracellular compartment provides essential iron required for growth. Infect Immun 63: 1478-1483.

77. Wolf R, Baroni A, Greco R, Corrado F, Ruocco E, et al. (2003) Quinine sulfate and HSV replication. Dermatol Online J 9: 3. 